\title{
Cardiovascular System Findings End Day
}

National Cancer Institute

\section{Source}

National Cancer Institute. Cardiovascular System Findings End Day. NCI Thesaurus. Code C123958.

The final day of the cardiovascular system assessment. 